\title{
The Learning Theory Jungle
}

\author{
Robert L. Minter, Ph.D., Walsh College, USA
}

\begin{abstract}
This paper explores the myriad of pedagogical and andragogical issues facing university educators in the student learning process, and focuses on how the proliferation of learning theories do not all apply to the adult learner.
\end{abstract}

Keywords: pedagogy; andragogy; learning theories; models of instruction; adult learning theory

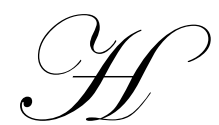

ow does a faculty member in higher education acquire the pedagogical knowledge base and skill set to become an effective educator? The answer, in most instances is that college and university faculty learn to teach by trail-and-error with little mentoring or coaching available to them. Some learn from their mistakes and some do not. The objective of this essay is to address the myriad of pedagogical and andragogical issues facing university educators in the student learning process.

Irony exists in the qualifications needed to teach in higher education when compared to qualifications needed to teach $\mathrm{K}-12$. Those who choose a full-time university teaching career seldom qualify to teach full-time without having a master's degree at a minimum, with the doctoral degree as the preferred credential. Adjunct instructors will usually find university employment requiring only the master's degree. In most instances, regardless of degree level, the majority of university faculty may be illiterate or semi-illiterate about the theories and practices relating to pedagogy and andragogy. If this be the case, faculty may possess little knowledge of student learning theories, teaching methodologies, and student motivational concepts.

However, those who desire to pursue teaching careers at K-12 levels in most states within the U.S. are required to fulfill the following entry level educational criteria: Bachelor's degree, teaching internship, teacher certification and an acceptable grade point average. In addition, to continue teaching, K-12 educators must annually accumulate professional educational units by attending courses and conferences in order to maintain their license to teach. The certified K-12 teacher probably has a broader base of pedagogical theory, learning models and instructional application skills than those who teach at the university level.

The following material will briefly explore the proliferation of learning theories in an attempt to develop awareness among faculty who teach at the university/college levels that not all theories of learning apply to the adult learner. In doing so, it is hoped that university faculty will question what assumptions about the adult learning process are guiding their teaching styles.

\section{THE LEARNING THEORY JUNGLE}

Multiple learning theories and models on pedagogy and andragogy represent a jungle of concepts that can be confusing, conflicting, and not fully validated by substantial research. The following categories of learning theories represent the myriad of mainstream concepts available for one to review:

\footnotetext{
- $\quad$ Anchored instruction theories

- $\quad$ Andragogy

- $\quad$ Aptitude-treatment interaction theories

- $\quad$ Attribution theories

- Behavioral theories

- $\quad$ Bottom-up models

- $\quad$ Cognitive theories
} 


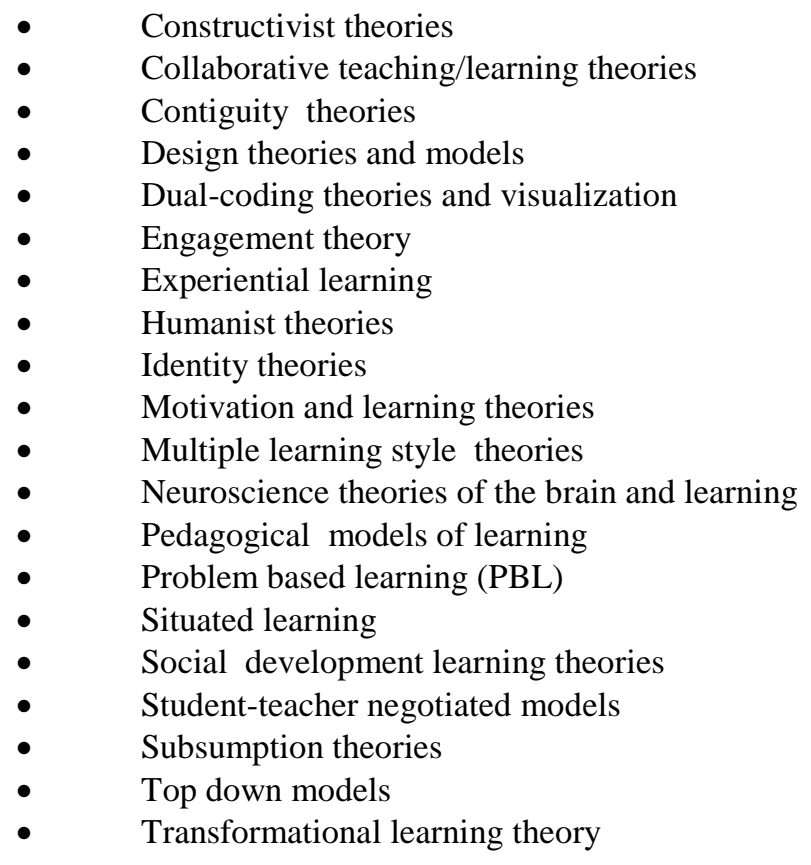

The above list of theories and recommended reading is not meant to be inclusive, but is offered to illustrate the numerous learning theory concepts available to faculty. A glossary of these learning theories and a bibliography of recommended reading on learning theories is included in the appendix.

Many of these theories overlap, have their proponents and critics, and have their advantages and disadvantages. At this stage of development, it is safe to say that these theories have not established significant validity from the research sector to say that there is one set of major theories that are generalizable across studentlearning environments at the college level (Beder, Darkenwald, Spring 1982, pp. 142-155; Gorham, Summer 1985, pp. 192-209).

The plethora of learning theories and available models of instruction can be extremely confusing to those of us who are looking for the right approaches to becoming effective instructors whether it be online instruction, blended, or totally onground. To further confound the learning theory jungle, many of the theories do not differentiate between pedagogy (pre-adult learning) and andragogy (adult learning).

The jungle of theories and proposed models of instruction, however, should be viewed by faculty as a rich resource to gain introspection into the complex world of teaching and learning. At best, this author believes that teaching is both a science and art of application. One can be knowledgeable of learning theories but be ineffective in the ability to apply them to pre-adult or adult learners. Effective teaching requires that one take the best of what theories have to offer and apply the concepts in artistic ways within the classroom.

On many days, college instructors leave the classroom scratching their heads and wondering what they have accomplished with their students, and what should they be doing differently. When these feelings occur, faculty need to engage in a track down process to figure out what may not be working and what to do differently.

During this track down, faculty should reflect on their personal "gogy" of teaching and learning that will be used in the classroom. Although there is not total agreement in the educational profession on appropriate "gogy" practices, there is a vast body of literature that differentiates between the theories of pedagogy and andragogy and their representative teaching models and student-centered learning concepts. 


\section{Pedagogical Model Assumptions}

The literature suggests that traditional pedagogical models and methods of teaching primarily apply to nonadult learners and are inappropriate to use with the adult learner (Henschke, 1998). Those subscribing to this school-of-thought believe that the pedagogical model is more applicable to the K-12 learning environment than with adult learning. Basic assumptions of the traditional pedagogical model emphasize some of the following assumptions (Freire, 1993):

- $\quad$ The instructor should be prescriptive in terms of what students will learn.

- $\quad$ The instructor's primary mission should be more directive than interactive with students in the classroom. The dynamic here is to place students in a more passive than active role in the learning process.

- The instructor should devote most of his/her class time communicating information to the students, with the expectation that they will put to memory what the instructor considers to be essential information (for which they will be tested on at some later date).

- $\quad$ The instructor assumes that non-adult learners do not have the motivation or maturity to be self-directed learners. In other words, they cannot be totally trusted on their own to employ self-motivation to manage their learning style, to meet deadlines, to focus on course and learning objectives, or to engage in the critical inquiry of knowledge process.

- $\quad$ The teacher assumes that students in general cannot manage their time very well and, consequently, require a high level of structure and close supervision.

\section{Andragogical Model Assumptions}

On the other hand, the andragogical model operates on the premise that, when teaching adults, the instructor should be utilizing different teaching methods and practices than those prescribed by the pedagogical model. The practice of andragogy operates on the following assumptions (Smith, 1999):

- $\quad$ Adult learners take on responsibility to be self-directed.

- $\quad$ Adult learners come into the classroom with a wealth of work experience and abilities with the ability to transform the information they receive into meaningful cognitive and reality-based application.

- $\quad$ Adult learners are often driven by their need to know.

- $\quad$ Adult learners have a focus on what they aspire to be and consequently are internally motivated to direct their learning toward those goals.

- $\quad$ Adult learners desire an instructor who is student-centered and who places them in an active rather than passive learner role.

- $\quad$ The andragogical model assumes that many of the teaching theories and practices that work for adult learners will not be appropriate when teaching pre-adult students. The extension of this logic also assumes that what works for teaching pre-adult learners under the pedagogical model will not be well suited for the adult learner.

As university faculty, how often do we engineer our instructional efforts around the concepts of pedagogy vs. andragogy? In other words, what model of student learning is your modus operandi for teaching students? If you teach at both the undergraduate and graduate levels, how flexible are you in adapting your style to an undergraduate audience, to a graduate audience, or to a mixed audience if you are teaching dual level courses? One of the most difficult challenges for faculty is to determine if college students in their classrooms can be considered as adult learners.

As university and college educators, we profess some knowledge of what are the preferred (and perhaps best) methods to use in teaching one's subject matter. However, the assumptions underpinning the effectiveness of one's teaching style may be operating on questionable practices according to the pedagogy/andragogy paradigms.

A number of questions can be raised to stimulate this discussion of what is effective teaching and what promotes effective student learning. The following questions listed under the various classifications are by no 
means meant to be inclusive, and are offered to stimulate discussion about how we as professional educators should approach the student learning process. For example, how can an instructor engage in objective assessment to determine if the paradigm of one's instructional style for the student audience is based on the pedagogical or andragogical model.

Diagnostics are available that can assist college instructors to assess their style of teaching in terms of these models. However, the outcomes of these paper-and-pencil diagnostics are based on self-perceptions and may not be actually practiced in the classroom. The true validity measure of one's actual teaching style is to utilize a combination of methods such as paper-pencil teaching style diagnostics, student assessments, third party observations, and mentoring/coaching.

A simple beginning on this journey is to apply diagnostic inquiry into how one goes about engineering the teaching-student learning dynamic. As mentioned previously, there are dozens of instructional and student learning paradigms that could be used in this journey. However, for the purposes of this essay, the author will utilize the pedagogy/andragogy model and mainly focus on the concepts and assumptions of andragogy as it relates to adult education at the college level.

\section{TRACK DOWN PROCESS}

To begin with, several andragogical components for inquiry are listed below as they relate to the instructor's analysis of the student audience, the construction of the syllabus, the management of the classroom dynamics, and the instructor's two-way communication and feedback style:

\section{Audience Analysis}

1. What pedagogical/andragogical assumptions are you making about your prospective students?

2. Will they have the appropriate prerequisites for the material to be covered?

3. What will be their age ranges and levels of work experience?

4. What will be the ethnic demographics and cultural differences in the way students approach learning?

5. What teaching model and its related assumptions (pedagogical or andragological) will direct your teaching practices?

\section{Syllabus Information}

1. Do you view the content of your syllabus to be a contract with the student?

2. Is your syllabus reflective of the teaching model you intend to employ?

3. Does your syllabus provide the direction for students to understand your expectations as they enter your instructional space? How do you know?

4. Does your syllabus identify the course core competencies and skill sets you will hold students accountable for in the assessment process?

5. Does your syllabus allow for cumulative testing of learning objectives, core competencies and requisite knowledge? (Research indicates that learner retention of information improves when faced with cumulative rather than noncumulative examinations.)

6. Does your testing methodology allow for students to experience a variety of assessment experiences that go beyond machine scored examinations?

7. How do you know that your testing practices assess higher levels of student learning and critical thinking?

8. Does your syllabus contain both course objectives and learning objectives, and are these differentiated for the student? (Faculty often do not recognize the major differences between these two types of objectives. Not all course objectives need to be assessed. The learning objectives are meant to assess the core competencies and skills sets that are identified in the syllabus.)

9. Does your syllabus reflect a "lazy evaluator" syndrome? (That is an overemphasis on objective scored examinations or an overemphasis on "soft skill" intuitive assessments.)?

10. Are the rubrics you use to evaluate student performance clearly stated? How do you know? 
11. How much of your course content will be engineered around "Need-to-Know" vs. "Nice-to-Know" information?

12. Does the textbook for the course enhance your ability to encourage student-centered learning and andragogical instructional practices?

13. Does your syllabus communicate that the student is placed more in a passive rather than an active studentcentered learner role?

\section{Communication And Feedback Style}

1. Are your team assignments assessing both individual and team outcomes?

2. How do you measure individual learning of leadership with team-based assignments?

3. What degree of student-instructor interaction is planned for in your course?

4. Do your students have the opportunity to provide periodic anonymous feedback regarding your instructional style and subject matter relevancy?

5. Do you solicit student feedback regarding comprehension roadblocks that they may be experiencing?

6. Do your students come to you only when they have a problem?

7. Do students have the opportunity at various points in the course to provide suggestions for re-engineering the course rather than just providing isolated suggestions for improvement?

8. Do you know how many minutes during normal class time are utilized by you in responding to student interaction and feedback? The shorter the time period allocated for interaction suggests a passive (more pedagogical) environment is being nurtured by the instructor.

9. Do students have opportunities to provide you with feedback on their perception of your communication style?

10. Do you encourage students to challenge the concepts and knowledge base delivered by you in class?

11. How do you work with the silent majority in your instructional efforts?

12. Do you engineer opportunities for high performers to interact with mid to low performers in your class?

13. Are you willing to make real-time adjustments to your syllabus and course content based on student feedback?

14. Do you engage in a self-diagnostic after each class regarding the communication dynamics that did or did not take place with your students? How does this reflection influence your ongoing communication style with the students?

15. How do test results you receive at various junctures of the course influence your instructional style and instructional practices?

16. How do your students value the opportunity to experience student- to-student and student-to-instructor interaction?

17. Do you overuse power point in the classroom? This nurtures passive learning.

18. What are your positive and negative stereotypes of students, and how do these influence your instructional efforts and communication style?

Based on your review of the assumptions of the two models (pedagogical and andragogical), and on your responses to the above questions, what teaching model assumptions do you see yourself primarily subscribing to pedagogy or andragogy? Based on your track down analysis, what changes do you feel are needed to increase your instructional effectiveness?

When involved in discussions with your colleagues relating to "What is the best modeling approach for effective teaching with the adult learner?," you probably have experienced that there is no one pure model that practicing educators follow or completely agree upon. Discussions generally reveal that many of us subscribe to a mixed model of learning theory and practice. In doing so, we may not even be aware of what theory or model of learning we are attempting to implement in our classrooms. Often, what we do in our instructional efforts is based on our own "intuitive model" without knowing whether learning theory or research support our instructional initiatives. 


\section{THE LEARNING ORGANIZATION}

Another paradox can be observed when one analyzes the mission of one's university. College missions generally emphasize that one of its primary core values focuses on instructional effectiveness and student learning. However, seldom in university mission statements or strategic plans will one find emphasis on creating a learning organization within its own academic culture.

As an academic and college administrator over the past thirty years, personal observation reveals that fulltime faculty are highly independent and seldom share (or take the time) to discuss their teaching practices and outcomes. Seldom do they share their teaching successes and failures. The dynamic of "sharing" appears to be almost non-existent for adjuncts. An important element of learning organization theory indicates that sharing of professional practices (both successes and failures) and turn around instructional strategies must take place if an institution of higher education is to become a learning organization. Without creating a learning organization culture, continuous improvement will only become a buzzword within the "halls of ivy."

Several questions are offered for your engagement in assessing the learning organization dynamics that may or may not be happening at your college/university:

1. How often within your department, discipline or college are opportunities provided for the instructional staff to discuss and challenge existing instructional practices and assumptions in light of the growing body of research and knowledge related to pedagogy and andragogy?

2. How does a college or department assure that what faculty do in the classroom is designed to effectuate cumulative long-term learning?

3. Is there common agreement among your colleagues regarding student-centered learning practices that should be employed within your discipline?

4. How does your department or discipline assure that teaching practices support student-centered learning in an attempt to reduce student passivity in the classroom?

5. Do your colleagues discuss and challenge the flow of course relationships to support long-term student cumulative learning expectations of various core competencies and skill sets?

Flow analysis of course work often reveals that core competencies addressed in courses taken in the previous semester are seldom reinforced in the next semester's course work. For example, students in a program that requires two courses in statistics, may take one course one semester and not take the second statistics course until one or two semesters have passed. In the meantime, courses taken during this gap period may not have anything to do with the statistical core competency of the program. Consequently, the gap between the two statistics courses, and the lack of reinforcement of courses and statistics taken during the gap period, will seriously affect the recall and cumulative learning for any student.

\section{CONCLUSION}

College educators involved with the adult learner should become cognizant of the many theoretical approaches available to them when working with the dynamics of pre-adult and adult learners. University educators should also nurture dialogue on their own campuses about establishing an organization learning climate. Communication with colleagues can be initiated by discussing the questions mentioned above, by discussing selected models of teaching and learning, by discussing pedagogical and adragogical concepts, and by sharing educational experiences with colleagues. In doing so, keep in mind that "one size does not fit all" student learners. Communicating with other faculty on the critical components of student learning and instructional style will be one step forward in creating an organizational learning climate within your university. 


\section{AUTHOR INFORMATION}

Dr. Minter is currently Executive Vice President and Chief Academic Officer and professor at Walsh College of Accountancy \& Business, Troy, MI. He has been a Dean of Business Colleges at: Delaware State University, Texas Wesleyan University, Cleveland State University, University of Northern Iowa, University of Michigan-Dearborn and Central Connecticut State University. He has a Ph.D. in Organizational Communication and Industrial Relations from Purdue University. Both his Master of Arts and Bachelor of Arts Degrees are from Miami University of Ohio.

\section{REFERENCES}

1. $\quad$ Beder, H.W. \& Darkenwald, G.G. (Spring 1982) Differences between Teaching Adults and Pre-Adults: Some Propositions and Findings. Adult Education 32, no.2: 142-155. (ERIC No. EJ 262 809).

2. Freire, Paulo, (1993) Pedagogy of the Oppressed. New York: Continuum Books. Chapter 2

3. Gorham, J., (Summer 1985) Differences between Teaching Adults and Pre-Adults: A Closer Look. Adult Education Quarterly 35, No. 4. pp. 194-209. (ERIC No 1 EJ 317 833).

4. Henschke, John A (1998); Historical Antecedents Shaping Conceptions of Andragogy; A Comparison of Sources and Roots. In Proceedings of the International Conference on Research in Comparative Andragogy, Radovljica, Slovenia. 


\title{
APPENDIX
}

\author{
Glossary Of Learning Theory Concepts
}

- Anchored instruction theories. Students role play a problem -based case while analyzing and solving the problem.

- Andragogy. Teaching adults requires different instructional assumptions and strategies that are to be utilized by the teacher about how one learns at the adult level in contrast to what is used with pre-adult students.

- Aptitude-treatment interaction theories. The optimal learning results when the instructor customizes material and opportunities for the learner.

- Attribution theories. Attempts to explain why students do what they do by determining the cause of a learning event or behavior.

- Behavioral theories. There are three types of behavior learning- based theories involved here: 1) contingent Theory, classical response conditioning theory, and operant or instrumental conditioning.

- Bottom- up models. Emphases is on the student to assume the responsibility to learn and places less responsibility on the instructor.

- Cognitive theories. Learning process links information that was once learned with the new information being learned.

- $\quad$ Constructivist theories. Assumes learning is best accomplished by having students learn by experimentation and not by being told what should be the end result.

- Collaborative teaching/learning theories. These are dependent on faculty collaboration and co-teaching strategies involving student participation in the process.

- Contiguity theories. Rewards and punishment do not have a significant role in learning taking place on a single trial since learning occurs after the association is made by the student between the stimulus and event

- Design theories and models. These theories emphasizes that content to be learned should be organized from simple to complex order for the student.

- Dual-coding theories and visualization. The method focuses on the processing of both verbal and visual objects which allow for dual coding of information and learning.

- $\quad$ Engagement theory. Designing learning tasks and activities that are perceived by students as relevant and challenging in order to produce optimum performance.

- Experiential learning. A four stage holistic theory of learning combining experience, perception, cognition and behavior.

- Humanist theories. Emphasizes learning through observing the behavior of others. Individuals model appropriate behavior for students to observe.

- Motivation based learning theories. Focus is on individual student goals and instructional strategies to assist students to achieve these goals.

- Multiple intelligence learning theories. Proposes several ways that people can learn: linguistically, logicalmathematical, visual-spatial, body-kinesthetic, musical-rhythm, interpersonal, intrapersonal.

- Neuroscience theories of the brain and learning. Advocates that the human brain can change structurally and functionally by the learning experiences students are exposed to by faculty and throughout life. Designing learning environments (e.g., how we teach and the learning experiences provided students) can have a significant impact on brain growth and development.

- $\quad$ Pedagogical model of learning. Develops a set of pre--adult assumptions that apply primarily to K-12 students. Instructional strategies are guided by these assumptions of learning and do not normally apply to the andrgogy of adult learning.

- $\quad$ Problem based learning (PBL). Instructional approaches that provide students with hands-on, active learning while investigating real problems. Relies heavily on student teams in the learning process.

- Situated Learning. Proposes that learning is unintentional and is situated within the student's exposure to activity, context and culture.

- $\quad$ Social development learning theories. Proposes that students can learn new information and behaviors by observing others. Three basic models of observational learning are: 1) Live modeling involves a person demonstrating a behavior to be learned; 2) Verbal modeling provides descriptions and illustrations of a desired behavior; 3) Symbolic modeling involves fictional characters (in books, movies, television or other media forms) that provide role model behaviors to be learned.

- Student-teacher negotiated models. Contractual agreements are established (often in writing and signed by the student and faculty member, and sometimes by the parent) in terms of student learning goals, personal commitment to these goals, and expected outcomes.

- Subsumption theories. Students learn meaningful information from verbal and textual presentations.

- $\quad$ Top down models. Teacher-delivered, direct instruction with little opportunity for students to structure their learning environment. 
- Transformational learning theory. Emphasizes student engagement in reflective and critical thinking, being open to others' perceptions and being less defensive to new ideas.

\section{SUGGESTED READING}

Bigge, M.L. \& Shermis, S.S., Learning Theories for Teachers $\left(6^{\text {th }} 2003\right)$. Allyn \& Bacon Series

Merriam, Sharan B., The New Update on Adult Learning Theory: New Directions for Adult and Continuing Education $\left(1^{\text {st }}, 2001\right)$ Joesy Bass

Shunk, Dale, Learning Theories and An Educational Perspective $\left(6^{\text {th }}, 2011\right)$ Addison Wesley 
NOTES 